\title{
Quantitation of Circulating T and B Lymphocytes in Children with Whooping Cough
}

\author{
RICARDO BERNALES, (22) JAY EASTMAN, AND JOSEPH KAPLAN \\ Department of Pediatrics, Wayne State University Medical School, Children's Hospital of Michigan, Detroit, \\ Michigan, USA
}

\section{Extract}

The numbers of circulating $T$ and $B$ lymphocytes in seven children with whooping cough due to Bordetella pertussis and eight control subjects were determined. All the children with whooping cough had an absolute lymphocytosis (mean $29,142 / \mathrm{mm}^{3}$ vs. 5,225 / $\mathbf{m m}^{3}$ ) and by surface marker criteria both $T$ cells and $B$ cells were increased (mean $T$ cells, whooping cough $15,794 / \mathrm{mm}^{3}$ vs. 3,516 / $\mathrm{mm}^{3}$ controls; mean $B$ cells, $13,393 / \mathrm{mm}^{3}$ whooping cough vs. $1,706 / \mathrm{mm}^{3}$ controls). However, the ratios of $T$ cells to $B$ cells in the whooping cough (1.4) and control group (1.9) did not differ significantly. This proportional increase in both $T$ and $B$ lymphocytes indicates that whatever mechanisms are responsible for lymphocytosis in $B$. pertussis infection affect both populations in a similar manner.

\section{Speculation}

Lymphocytosis in children with whooping cough results, primarily, from $B$. pertussis-induced blockage of $T$ and $B$ cell re-entry into lymph nodes from the blood. The profound effect of $B$. pertussis on lymphocyte recirculatien patterns might be of value in future attempts at "immunologic engineering."

B. pertussis infection of humans and experimental animals results in a striking increase in circulating lymphocytes $(8,12-15$, $20)$. Animal studies suggest that this lymphocytosis represents an increase in both $T$ and $B$ cells $(1,6,10)$ caused by a combination of two $B$. pertussis effects: blockage of lymphocyte re-entry into lymph nodes from the blood and increased lymphocyte release from lymphoid tissues into the circulation $(1,8,13-16,18)$. Whether the characteristic lymphocytosis seen in children with whooping cough results from these same mechanisms is not known. In the hope of shedding some light on this question we have determined the proportions and absolute numbers of circulating $\mathrm{T}$ and $\mathrm{B}$ lymphocytes in seven children with whooping cough due to $B$. pertussis. The results of these experiments demonstrate that the lymphocytosis seen in children with whooping cough results from a proportional increase in both $\mathrm{T}$ and $\mathrm{B}$ lymphocytes. This finding supports the concept that the changes in lymphocyte distribution and circulation which have been documented in experimental animals infected with $B$. pertussis also occur in man and suggests that the main mechanism of $B$. pertussis-induced lymphocytosis is blockage of lymphocytes re-entry into lymph nodes rather than increased release from lymphoid organs.

\section{MATERIALS AND METHODS}

\section{PATIENTS}

The patients' ages and diagnoses are shown in Table 1. The seven children with whooping cough ranged in age from 1-11 months. All were admitted to the Children's Hospital of Michigan between September 1974 and February 1975, all were in the paroxysmal stage of whooping cough when studied, and all had positive nasopharyngeal cultures for $B$. pertussis. Control subjects were eight afebrile, nonimmunosuppressed children from 1-24 months of age. Informed consent was obtained.

\section{QUANTITATION OF T AND B LYMPHOCYTES}

White counts and differentials were performed on capillary blood obtained by finger stick. Total white counts were measured with a hemocytometer. Differential counts were performed by examination of Wright-stained preparations. T and B cell marker determinations were performed on peripheral blood lymphocytes obtained by Ficoll-Hypaque separation (2). The percentages of cells which formed rosettes with sheep erythrocytes (E rosettes), a $\mathrm{T}$ cell marker, were measured as follows. A mixture of $2.5 \times 10^{5}$ lymphocytes and $2 \times 10^{7}$ sheep erythrocytes in $0.5 \mathrm{ml}$ Hanks' basal salt solution (HBSS) was incubated for $15 \mathrm{~min}$ at $37^{\circ}$, centrifuged at $600 \times g$ for $5 \mathrm{~min}$, and then further incubated for 90 min at $4^{\circ}$. The cells were then resuspended by gentle rotation, and a drop was placed on a slide and examined microscopically. At least 200 nucleated cells were counted and those binding three or more erythrocytes were considered positive. The percentages of cells with surface immunoglobulin, a B cell marker, were determined by direct immunofluorescence. A $0.2-\mathrm{ml}$ aliquot of $10^{6}$ cells was mixed with appropriately diluted fluorescein-conjugated polyvalent rabbit anti-human Ig from Hyland Labs, Los Angeles, Calif., in diluent consisting of HBSS with $20 \%$ fetal calf serum and $0.1 \%$ sodium azide. After $30 \mathrm{~min}$ of incubation at $4^{\circ}$ the cells were washed three times in diluent, suspended in $50 \%$ glycerol, and examined for surface fluorescence using a Zeiss fluorescence microscope with an HBO-200 w/4 mercury vapor lamp, excitation filter interference FITC, heat absorption filter $\mathrm{KGl}$, and red suppression filter BG38. At least 200 cells were counted per sample. The total numbers of circulating $\mathrm{E}$ rosette-positive cells and surface Ig-positive lymphocytes were then calculated as follows:

$$
\begin{aligned}
& \text { E rosettes } / \mathrm{mm}^{3}=\text { lymphocytes } / \mathrm{mm}^{3} \times \frac{\% \mathrm{E} \text { rosette }^{+}}{\% \mathrm{E} \text { rosette }}+\% \mathrm{SIg}^{+} \\
& \mathrm{SIg}^{+} \text {cells } / \mathrm{mm}^{3}=\text { lymphocytes } / \mathrm{mm}^{3} \times \frac{\% \mathrm{SIg}^{+}}{\% \mathrm{E} \text { rosette }}+\% \mathrm{SIg}^{+}
\end{aligned}
$$

The validity of this method of calculating total numbers of circulating $\mathbf{T}$ and $\mathbf{B}$ lymphocytes is based on the following observations: (I) the proportions of E rosette-positive and SIgpositive cells in suspensions of blood lymphocytes prepared by Ficoll-Hypaque separation closely parallel the proportions of such cells in unseparated blood (3); (2) monocytes, varying numbers of which are always present in such suspensions, are E rosette negative (9) and SIg negative (3); (3) only a very small proportion (0- 
Table 1. Patients tested

\begin{tabular}{crll}
\hline Patient & Age, mo & Sex & \multicolumn{1}{c}{ Diagnosis } \\
\hline 1 & 2 & M & Whooping cough \\
2 & 4 & F & Whooping cough \\
3 & 2 & F & Whooping cough \\
4 & 11 & M & Whooping cough \\
5 & 11 & M & Whooping cough \\
6 & 1 & F & Whooping cough \\
7 & 4 & F & Whooping cough \\
8 & 10 & F & Healed cellulitis \\
9 & 24 & M & Contusion forehead \\
10 & 2 & M & Pyloric stenosis \\
11 & 2 & M & Bronchopulmonary dysplasia \\
12 & 3 & M & Failure to thrive \\
13 & 2 & M & Sturge-Weber syndrome \\
14 & 2 & M & Skull fracture \\
15 & 2 & M & Failure to thrive \\
\hline
\end{tabular}

$5 \%$ ) of peripheral blood lymphocytes are both $\mathrm{E}$ rosette negative and SIg negative (19).

\section{RESULTS}

Table 2 presents the results of determining the absolute numbers and percentages of lymphocytes with $\mathrm{T}$ or $\mathrm{B}$ cell properties in blood of patients with whooping cough and uninfected agematched control subjects. Cell counts and differential counts on samples of whole blood showed, as expected, that whooping cough patients, as a group, had strikingly elevated numbers of circulating lymphocytes compared with control subjects. T and B cell marker determinations on Ficoll-Hypaque-separated mononuclear cell preparations obtained from these same blood samples revealed that this lymphocytosis reflected significant increases in the absolute numbers of both sheep erythrocyte-binding cells and surface Ig-bearing cells. It should be noted that these numbers were calculated on the assumption that in children with whooping cough, as in normal subjects, only a small proportion of peripheral lymphocytes are both $E$ rosette negative and SIg negative. If, for some reason, whooping cough is associated with increased proportions of such cells in the circulation, the estimate of total T and B cell numbers in this group could be exaggerated by as much as $25 \%$. However, even when corrected for this possibility, it is still clear that these children had an absolute increase of both $\mathrm{T}$ and $\mathrm{B}$ cells in the circulation. The relative proportions of blood cells with these $\mathrm{T}$ or $\mathrm{B}$ cell surface markers in the whooping cough group were not, however, significantly different than the proportions of these cells found in the control group.

\section{DISCUSSION}

Our findings demonstrate that the lymphocytosis which occurs in children with whooping cough results from proportional increases in the numbers of circulating $T$ lymphocytes and $B$ lymphocytes. As measured by surface marker criteria, $T$ cells and $B$ cells are present in significantly greater numbers in FicollHypaque-separated mononuclear suspensions from blood of subjects with whooping cough than in uninfected control subjects. The proportions of these two cell types are not, however, significantly different from the proportions of $T$ cells and $B$ cells found in peripheral blood of normal children.

These findings can be interpreted in the light of current knowledge of lymphocyte production, tissue distribution, and circulation dynamics (7). Lymphocytes are produced in the thymus, bone marrow, spleen, and lymph nodes. Some of these leave their sites of production and enter the blood circulation. After having entered the blood stream lymphocytes eventually leave the circulation by entering the spleen or lymph nodes. A very
Table 2. Quantitation of circulating white cells, lymphocytes, and cells with $T$ or $B$ cells markers in whooping cough patients and control subjects

\begin{tabular}{|c|c|c|c|}
\hline & \multicolumn{2}{|c|}{$\begin{array}{l}\text { Whooping cough patients } \\
\qquad(n=7)\end{array}$} & \multirow{2}{*}{$\begin{array}{c}\text { Control } \\
\text { subjects } \\
(n=8)\end{array}$} \\
\hline & Mean \pm SE & $P$ & \\
\hline White blood cells $/ \mathrm{mm}^{3}$ & $45,371 \pm 15,692$ & $<0.05$ & $9,138 \pm 961$ \\
\hline Lymphocytes $/ \mathrm{mm}^{3}$ & $29,142 \pm 9,222$ & $<0.02$ & $5,225 \pm 898$ \\
\hline E rosettes $/ \mathrm{mm}^{3}$ & $15,794 \pm 4,399$ & $<0.02$ & $3,516 \pm 684$ \\
\hline $\begin{array}{l}\text { Surface Ig-positive } \\
\text { cells } / \mathrm{mm}^{3}\end{array}$ & $13,393 \pm 5,460$ & $<0.05$ & $1,706 \pm 306$ \\
\hline \% lymphocytes & $70 \pm 5$ & $>0.1$ & $57 \pm 6$ \\
\hline$\%$ E rosettes & $44 \pm 7$ & $>0.2$ & $51 \pm 4$ \\
\hline $\begin{array}{l}\% \text { Surface Ig-positive } \\
\text { cells }\end{array}$ & $31 \pm 3$ & $>0.2$ & $27 \pm 5$ \\
\hline
\end{tabular}

minor proportion enter the thymus and bone marrow. A passive process directly related to the numbers of lymphocytes in the splenic artery determines the numbers of blood lymphocytes which enter the spleen. In contrast, the numbers of blood lymphocytes which enter lymph nodes are regulated by the ability of these cells to pass through the walls of specialized postcapillary venules. This ability is, in turn, affected by lymphocyte surface membrane properties $(7,8,16)$.

From these considerations of lymphocyte kinetics it can be seen that three different mechanisms, either singly or in combination, could account for $B$. pertussis-induced lymphocytosis: $(I)$ increased lymphopoiesis, (2) increased lymphocyte release from thymus, bone marrow, spleen, or other lymphoid tissues, or (3) decreased lymphocyte entry into lymph nodes from circulating blood. Do the findings reported here support any one or more of these possibilities? If increases in either lymphopoiesis or tissue release were the only cause of lymphocytosis in whooping cough, our data would indicate that $B$. pertussis infection must induce an identical degree of enhanced production and/or release of $T$ cells and $B$ cells. This seems highly unlikely in view of the observations that $(l) \mathrm{T}$ cells and $\mathrm{B}$ cells are produced and reside in distinct anatomic sites, and (2) that each of these sites contain different proportions of the two cell types (5). A generalized inability of lymphocytes to re-enter lymph nodes from blood could, on the other hand, be expected to result in a proportional build-up of both $\mathrm{T}$ and $\mathrm{B}$ cells in the circulation. Therefore, although a component of increased lymphophiesis and/or increased lymphocyte release cannot be ruled out by our data, the results are more consistent with the concept that lymphocytosis in children with whooping cough results in large part from decreased lymphocyte re-entry into lymph nodes. This interpretation receives support from the fact that the lymphocytosis induced by $B$. pertussis in experimental animals has been shown to be caused mainly by an inability of lymphocytes to enter lymph nodes from the blood $(8,18,20)$.

The profound effects of $B$. pertussis on lymphocyte circulation dynamics suggest that $B$. pertussis organisms or extracts of $B$. pertussis might be useful in immunotherapy. For example, they might be employed in conjunction with leukophoresis as an alternative to thoracic duct drainage in lymphocyte depletion therapy. Alternatively, as suggested by their observed adjuvant activity in animals $(4,6,12,17)$, they might be useful as adjuvants in tumor immunotherapy. With these possibilities in mind we are currently attempting to determine whether $B$ pertussis vaccine administration in humans results in changes in lymphocyte distribution similar to those induced by natural infection.

\section{REFERENCES AND NOTES}

1. Anthanassiades, T. J., and Morse, S. I.: Lymphocytosis induced in mice by supernatant fluids of Bordetella pertussis cultures: A histopathological study. Blood, 42: 611 (1973). 
2. Böyum, A.: Isolation of mononuclear cells and granulocytes from human blood. Scand. J. Clin. Lab. Invest., 21: 776 (1968).

3. Brown, G., and Greaves, M. F., Enumeration of absolute numbers of $\Upsilon$ and $B$ lymphocytes in human blood. Scand. J. Immunol., 3: 16 (1974).

4. Clausen, C. R., Munoz, J., and Bergman, R. K.: Reaginic type of antibody in mice stimulated by extracts of Bordetella pertussis. J. Immunol., 103: 768 (1969).

5. Cooper, M. D., Peterson, R. D. A., and Good, R. A.: Delineation of the thymic and bursal lymphoid systems in the chicken. Nature, 205: 143 (1965).

6. Dresser, D. W., Wortis, H. H. H., and Anderson, H. R., The effect of pertussis vaccine on the immune response of mice to sheep red blood cells. Clin. Exp. Immunol. 7: 871 (1970).

7. Ford, W. L., and Gowans, J. C.: The traffic of lymphocytes. Semin. Hematol., 6: 67 (1969).

8. Iwasa, S., Yoshikawa, T., Fukumura, K., and Kurokawa, M.: Effects of the lymphocytosis-promoting factor from Bordelella pertussis on the function and potentiality of lymphocytes. I. Effect on the ability of lymphocytes to recirculate in the body. Japan J. Med. Sci. Biol., 23: 47 (1970).

9. Jondal, M., Holm, G., and Wigzell, H.: Surface markers on human T and B lymphocytes forming nonimmune rosettes with sheep red blood cells. J. Exp. Med., 136: 205 (1972).

10. Kalpaktsoglou, P. K., Yunis, E. J., and Good R. A.: Changes produced by pertussis antigen on the blood cells and lympho-haemopoietic tissues after early and late thymectomy of splenectomy. Clin. Exp. Immunol., 5: 91 (1969).

11. Kaplan, J., Mastrangelo, R., and Peterson, W. D., Jr.: Childhood lymphoblastic lymphoma, a cancer of thymus derived lymphocytes. Cancer Res., 34: 521 (1974).

12. Kind, L. S.: The altered reactivity of mice after inoculation with Bordetella pertussis vaccine. Bactiol. Rev., 22: 173 (1958).
13. Morse, S. I.: Studies on the lymphocytosis induced in mice by Bordetella pertussis. J. Exp. Med., 121: 49 (1964).

14. Morse, S. I., and Riester, S. K.: Studies on the leukocytosis and lymphocytosis induced by Bordetella pertussis. I. Radioautographic analysis of the circulating cells in mice undergoing pertussis-induced hyper leukocytosis. J. Exp. Med., 125: 401 (1967).

15. Morse, S. I., and Riester, S. K.: Studies on the leukocytosis and lymphocytosis induced by Bordetella pertussis. II. The effect of pertussis vaccine on the thoracic duct lymph and lymphocytes of mice. J. Exp. Med., 125: 619 (1967).

16. Morse, S. I., and Riester, S. K.: Studies on the leukocytosis and lymphocytosis induced by Bordetella pertussis. III. The distribution of transfered lymphocytes in pertussis-treated and normal mice. J. Exp. Med., 132: 663 (1970).

17. Pieroni, R. E., and Levine, L.: Adjuvant principle of pertussis vaccine in the mouse. Nature, 211: 1419 (1966)

18. Rai, K. R., Chanana, A. D., Cronkite, E. P., Joel, D. D., and Stevens, J. B. Studies on lymphocytes. III. Mechanism of lymphocytosis induced by supernatant fluids of Bordetella pertussis cultures. Blood, 38: 49 (1971).

19. Ross, F. D., Rabellino, E. M., Polley, M. J., and Grey, H. M.: Combined studies of complement receptors and surface immunoglobulin-bearing cells and sheep erythrocyte rosette-forming cells in normal and leukemic human lymphocytes. J. Clin. Invest., 52: 377 (1973)

20. Taub, R. N., Rosett, W., Odler, A., and Morse, S. I.: Distribution of labeled lymph node cells in mice during lymphocytosis induced by Bordetella pertussis. J. Exp. Med., 136: 1581 (1972).

21. This work was supported by the Kales fund.

22. Requests for reprints should be addressed to: R. Bernales, M.D., Georgetown University Medical Center, Gorman Bldg., Rm. 130, 3800 Reservoir Rd., N.W., Washington, D. C. 20007 (USA).

23. Accepted for publication June 4, 1976. uridine diphosphate glucuronyl transferase uridine diphosphate xylosyl transferase

\title{
Xylose, Glucose, and Glucuronic Acid Conjugation of Bilirubin in the Newborn Rat
}

\author{
SERGIC L. VAISMAN, KWANG-SUN LEE, AND LAWRENCE M. GARTNER ${ }^{(25)}$ \\ Division of Neonatology, Department of Pediatrics, The Rose F. Kennedy Center for Research in Mental Retardation \\ and Human Development and the Liver Research Center, Albert Einstein College of Medicine, Bronx, New York,
}

$U S A$

\section{Extract}

The development and relative contribution of hepatic bilirubin conjugation with glucuronic acid, xylose, and glucose was studied in vitro in newborn rats $1-20$ days old. In adult control rats, $75 \%$ of the conjugates formed were with glucuronic acid, whereas in 1-day-old newborns, only $50 \%$ of the conjugates were with glucuronic acid $(P<0.02)$ while xylose and glucose conjugates of bilirubin together were equal to that of glucuronic acid. By day 4 , total conjugating capacity increased to adult levels and a mature pattern of distribution. In response to phenobarbital treatment, xylose and glucose conjugation increased 4 days earlier than glucuronide conjugation and maximal induction occurred 8 days sooner for nonglucuronide conjugation than for glucuronide.

\section{Speculation}

The pattern of enzyme maturation and relative activities of the various bilirubin conjugating systems in newborn rats cannot be extrapolated to those in the human, but this study suggests that a similar study in the human or subhuman primate might demonstrate that glucose and xylose conjugation compensate, in part, for deficient glucuronide conjugation.

In mammalian species bilirubin is conjugated primarily with glucuronic acid at the site of the hepatic endoplasmic reticulum (microsomes) to form the water-soluble form of bilirubin for excretion into bile. It has long been recognized that fetal and newborn liver of all species is deficient in capacity to form the glucuronide conjugate of bilirubin because of marked reduction in bilirubin glucuronyl transferase activity $(2,13,20)$. Recent study in newborn monkeys has demonstrated that the inability of the newborn liver to form bilirubin conjugates is largely responsible for the early phase of physiologic jaundice $(7,8)$.

Other carbohydrate conjugates of bilirubin, in addition to glucuronides, are formed in all species studied thus far, as has been demonstrated in vitro $(4,5)$ and by chromatographic separation of the pigments in bile $(4,11)$. These studies have been limited to the adult age group and the formation of nonglucuronide conjugates by the fetus and newborn has never been examined. Consideration must be given to the possibility that nonglucuronide conjugates of 